\title{
Receita de contrato com cliente (IFRS 15 / CPC 47): aspectos contábeis do segmento de medicina diagnóstica no Brasil
}

\author{
Revenue from contracts with customers (IFRS 15 / CPC 47): \\ accounting aspects of the diagnostic medicine industry in Brazil \\ Ingresos de contrato con cliente (IFRS 15 / CPC 47): \\ aspectos contables del segmento de medicina diagnóstica en Brasil
}

\section{Carlos Elder Maciel de Aquino}

Mestre em Ciências Contábeis e Atuariais pela Pontifícia Universidade Católica de São Paulo (PUC-SP)

Professor da Fundação Instituto de Pesquisas Contábeis, Atuariais e Financeiras (FIPECAFI)

Endereço: Rua Coronel Lisboa, 395 - apt. 141-B - Vila Mariana

CEP: 04020-040 - São Paulo/SP - Brasil

E-mail: ce.aquino@uol.com.br

Telefone: (11) 5573.7513 / (11) 96931.1305

\section{Sérgio de Iudícibus}

Doutor em Contabilidade e Controladoria pela Universidade de São Paulo (USP)

Professor de Pós-graduação da Pontifícia Universidade Católica de São Paulo (PUC-SP)

Endereço: Rua Monte Alegre, 984 - Perdizes

CEP: 05014-901 - São Paulo/SP - Brasil

E-mail: siudicibus@pucsp.br

Telefone: (11) 3670.8000

\section{Fernando de Almeida Santos}

Doutor em Ciências Sociais pela Pontifícia Universidade Católica de São Paulo (PUC-SP)

Professor de Pós-graduação da Pontifícia Universidade Católica de São Paulo (PUC-SP)

Endereço: Rua Raul Pompéia, 229 apto. 24 Bairro Pompéia

CEP: 05025-010 - São Paulo/SP - Brasil

E-mail: almeidasantos@pucsp.br

Telefone: (11) 9811.61455

\section{Antonio Saporito}

Doutor em Contabilidade e Controladoria pela Universidade de São Paulo (USP)

Professor do Departamento de Contabilidade da EPPEN da Universidade Federal de São Paulo (UNIFESP)

Endereço: Rua Angélica, ${ }^{\circ} 100$ - Jd. das Flores

CEP: 06110-295 - Osasco/SP - Brasil

E-mail: saporito@unifesp.br

Telefone: (11) 2284-6900

Artigo recebido em 28/05/2019. Revisado por pares em 07/10/2019. Reformulado em 27/11/2019. Recomendado para publicação em 30/11/2019 por Carlos Eduardo Facin Lavarda (Editor-Chefe). Publicado em 24/04/2020. 


\title{
Resumo
}

Com a publicação da IFRS 15 - Revenue from Contracts with Customers as companhias passaram a reconhecer a receita de contrato com cliente numa base comum de princípios e orientações voltadas a determinar quando reconhecer receita e o valor que deve ser reconhecido. Este estudo verifica a aderência de empresas do segmento de medicina diagnóstica no Brasil à IFRS 15 / CPC 47. Não foram encontradas pesquisas que abordam o setor de saúde no Brasil. Esta pesquisa é caracterizada como exploratória, qualitativa e descritiva. Evidenciou-se que as empresas atendem aos requerimentos regulatórios para reconhecimento, mensuração e registro contábil, porém, não estão aderentes aos aspectos de uniformização, completude e transparência das informações divulgadas. Portanto, esta pesquisa contribui para a qualidade e padronização de registros, apresentação e divulgação contábil do ciclo de receita, permitindo avaliação de performance na gestão de recebíveis e melhor comparação entre empresas.

Palavras-chave: Reconhecimento de receita; IFRS 15; CPC 47; Setor de Saúde; Harmonização

\begin{abstract}
With the publication of IFRS 15 - Revenue from Contracts with Customers, the companies began to recognize contract revenue from customers on a common basis of principles and guidelines to determine when to recognize revenue and the amount that should be recognized. This study verifies the adherence of companies from the diagnostic medicine industry in Brazil to IFRS 15 / CPC 47. It was evidenced that the companies meet the minimum regulatory requirements for recognition, measurement and accounting registration, however, they are not adherent to the aspects of standardization, completeness and transparency of the disclosed information.
\end{abstract}

Keywords: Revenue Recognition; IFRS 15; CPC 47; Healthcare System; Harmonization

\section{Resumen}

Con la publicación de la IFRS 15 - Revenue from Contracts with Customers, las compañías reconocieran los ingresos de contrato con el cliente sobre una base común de principios y directrices orientadas a determinar cuándo reconocer ingresos y el valor que debe reconocerse. Este estudio verifica la adherencia de empresas del segmento de medicina diagnóstica en Brasil a la IFRS 15. Se evidenció que las empresas atienden a los requisitos mínimos regulatorios para el reconocimiento, la medición y el registro contables, sin embargo, no están adheridos en términos de uniformidad, completitud y transparencia de las informaciones divulgadas.

Palabras clave: Reconocimiento de Ingresos; IFRS 15; CPC 47; Sector de Salud; Armonización

\section{Introdução}

Reconhecer a receita de contrato com cliente, de forma que atenda à harmonização contábil internacional, tornou-se um desafio necessário, principalmente para setores de mercado com peculiaridades em relação ao seu ciclo financeiro.

Estudos recentes sobre a IFRS 15 foram realizados em setores como o da construção civil e incorporadoras imobiliárias (CAMPOS, 2017; CARPIS DANI et al., 2017; FAGUNDES, 2017; SOUZA, 2015; TAVARES, 2016), de transporte (SILVA, 2018), de óleo e gás (PEREIRA, 2017; SPARGER, 2017) e outros de aplicação geral em empresas brasileiras e de outros países (BENAVIDES, 2015; COVA, 2015; KHAMIS, 2016; KNOROVÁ, 2016; MORA et al., 2015; ONCIOIU; AVAKUMOVIC, 2016; OYEDOKUN, 2016; PASQUALE, 2017; PETERS, 2016; SEVERIANO et al., 2017; YEATON, 2015), os quais exploraram a dificuldade na adoção da nova norma, principalmente por ser de aplicação geral, requerendo análise minuciosa para aplicação em cada segmento do mercado. Reconhecem, porém, que se trata de evolução importante, dado que o novo padrão fornece um modelo contábil único e abrangente para o reconhecimento de receita. 
Há exemplos de estudos realizados sobre receita de serviços com cliente à luz da IFRS 15 que exploram o impacto da nova regulamentação no setor de saúde na Europa e nos Estados Unidos (CONNER, 2017; HOLLOWAY et al., 2017; KATZ, 2017; MCKEE, 2015; MUNTER, 2016; JOHNSON, 2018), porém, não foi encontrada evidência de estudo explorando o setor de saúde no Brasil, muito menos com foco no segmento de medicina diagnóstica. Há estudo no setor de saúde no Brasil (foco em hospital), porém, ainda com referência à regulamentação vigente anteriormente a IFRS 15 / CPC 47 -Receita de Contrato com Cliente (MAES et al., 2006; SILVA, 2012).

No âmbito do segmento de fornecedores de serviços auxiliares de apoio ao diagnóstico SAD ou de medicina diagnóstica (inclui análises clínicas; diagnóstico por imagem e métodos gráficos; medicina nuclear e citologia e anatomia patológica), esse reconhecimento torna-se bastante desafiador, visto envolver contratos com entes públicos, com operadoras de planos de saúde, com pessoas físicas e numa relação lab-to-lab (terceirização de serviços de um laboratório com outro). Agrava-se ao se considerar que os serviços podem sofrer glosas em data posterior ao fato gerador da receita, o que pode distorcer a receita anteriormente reconhecida.

Este estudo verifica a aderência de empresas do segmento de medicina diagnóstica no Brasil à IFRS 15 / CPC 47 e, quando aplicável, oferece sugestões de melhoria ao modelo de registro, apresentação e divulgação contábil, de forma que permita um melhor entendimento das peculiaridades do segmento e gere uma informação de melhor qualidade, portanto, mais útil para a tomada de decisão pelos usuários. Segue o preceito de que os registros contábeis precisam ser consistentes no tempo para permitir uma análise precisa e comparável.

Considera, por fim, aspectos da ocorrência do fato gerador, da mensuração e momento de reconhecimento da receita de contrato de cliente e sua divulgação, à luz da Estrutura Conceitual para Elaboração e Divulgação de Relatório Contábil-Financeiro (CPC 00), da IFRS 15 / CPC 47 e da IFRS 9 / CPC 48 - Instrumentos Financeiros.

Para investigar o problema proposto, buscou-se responder às seguintes questões: (i) Como se dá o processo de reconhecimento, mensuração e contabilização da receita com cliente no ciclo financeiro das empresas? (ii) Quais os critérios adotados para o reconhecimento e registro de perdas por inadimplência e por glosas de serviços prestados? (iii) Qual o disclosure que é dado sobre receita com cliente? (iv) $\mathrm{O}$ que deve ser proposto para prover maior transparência, completude e comparabilidade às informações contábeis do ciclo de receita?

\section{Referencial Teórico}

\subsection{Estrutura conceitual de contabilidade}

O avanço e consolidação da globalização econômica, especialmente a mobilidade internacional do capital financeiro permitem às empresas maior acesso aos mercados de crédito e de capitais e facilitam as suas internacionalizações. Portanto, por meio da expansão geográfica, lançou o desafio de se ter um padrão internacional de contabilidade para facilitar o entendimento e comparabilidade das demonstrações contábeis por parte de seus usuários.

Neste contexto, Yamamoto, Paccez e Malacrida (2011, p. 1) reforçam que "atualmente, nesse cenário de globalização, têm-se buscado não somente a transparência das informações, mas a convergência internacional das normas contábeis."

Percebe-se, assim, a importância de se adotar padrões contábeis internacionais para nortear os registros e as apresentações das demonstrações contábeis pelas entidades, pois possibilita o uso de uma linguagem contábil comum e de maior acesso para os usuários. Permite, também, a comparabilidade de informações, abrindo fronteiras para a inserção de empresas nos mercados de crédito e de capitais de países com a mesma taxonomia. 
O Conselho Federal de Contabilidade (CFC) entendeu que a convergência do padrão contábil brasileiro às normas internacionais viria contribuir com o desenvolvimento sustentável do país, promovendo maior transparência das informações financeiras utilizadas pelo mercado.

Pela Lei n. 11.638 (2007), o Brasil buscou harmonizar o padrão contábil brasileiro às Normas Internacionais de Contabilidade, emitidas pelo International Accounting Standards Board (IASB). Foi emitido, então, pela CVM, o atual CPC 00 (R1) - Estrutura Conceitual para Elaboração e Divulgação de Relatório Contábil-Financeiro, elaborado a partir do The Conceptual Framework for Financial Reporting (BV 2011 Blue Book), emitido pelo IASB.

\subsection{Princípios fundamentais de contabilidade versus características qualitativas da informação contábil útil}

A nova estrutura conceitual contábil editada pela CVM (CPC 00, 2013, pp. 7-46) está alicerçada na ênfase a aspectos qualitativos das demonstrações contábeis, como prudência e a primazia da essência econômica sobre a forma jurídica, bem como adota como pressupostos básicos os regimes de Competência e Continuidade.

Convenções como Relevância e Materialidade são tratadas como características qualitativas da informação contábil-financeira útil, portanto, são reputadas como informações mais úteis para os stakeholders existentes ou potenciais e para tomada de decisões acerca da entidade que reporta informação contábil-financeira).

O regulador, também, se preocupou em caracterizar e classificar as informações em função de sua utilidade para os usuários tomarem boas decisões em relação à entidade que reporta as informações. Neste contexto, criou dois grupos de informações: as denominadas (i) características qualitativas fundamentais, representadas por relevância e representação fidedigna, logo confiabilidade, e as denominadas (ii) características qualitativas de melhorias, representadas por comparabilidade, verificabilidade, tempestividade e compreensibilidade. A Figura 1 mostra a estrutura para a caracterização da informação contábil útil.

O último grupo qualifica o primeiro, sendo que, assim se verifica uma hierarquia, em que as características qualitativas de melhorias, individualmente ou em grupo, não podem tornar a informação útil se a informação sobre o fenômeno econômico não for relevante ou não representar com fidedignidade a realidade reportada.

Exigências de divulgação qualitativa e quantitativa visam ajudar os usuários a entender a natureza, montante, momento e a incerteza em relação à receita com clientes e seus fluxos de caixa futuros. Decisões assentadas em informação de qualidade tendem a ser melhores.

Dadas as características individuais e de cada grupo de usuários, pode não ser possível fornecer toda informação entendida por estes como relevante. Isto torna crucial que a informação produzida seja efetivamente útil para a tomada de decisão econômica, sob a ótica de sua importância, disponibilidade dos dados e custo de elaboração e divulgação. 
Figura 1: Características da informação contábil útil

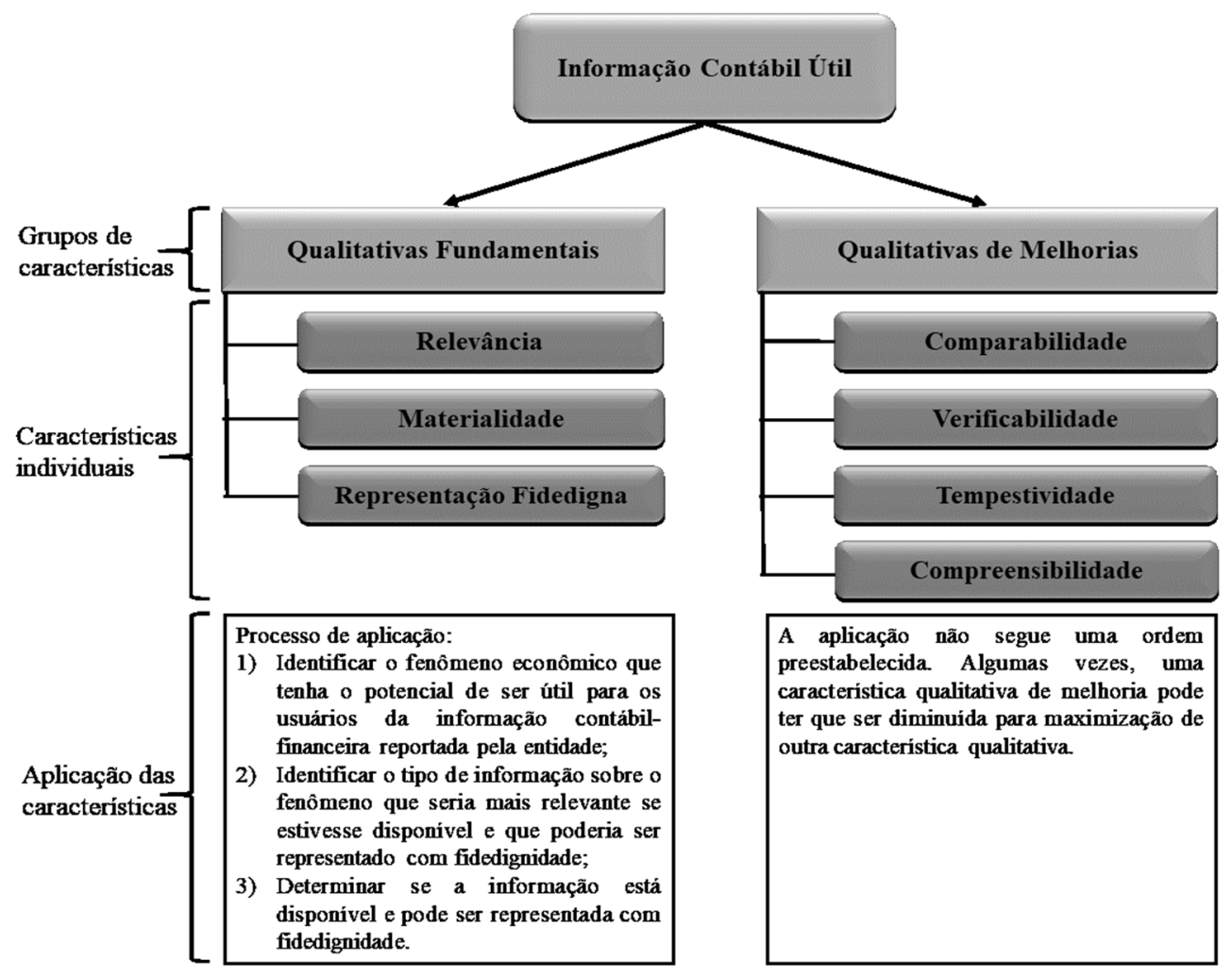

Fonte: Elaborada pelos autores com base no CPC 00.

\subsection{Receita de Contrato com Cliente}

As orientações para o registro contábil de receita de clientes têm sido um desafio para os reguladores nas últimas décadas, principalmente por abrigar empresas de naturezas diferentes e de segmentos diversos, o que dificulta a estruturação e aplicação de regra única para o tratamento de todas as especificidades dos negócios.

No intuito de regular e dotar de melhor padronização, transparência e comparabilidade das práticas entre entidades, ao longo do tempo vários reguladores legislaram a respeito do reconhecimento, mensuração, registro e divulgação de receitas de clientes. $\mathrm{O}$ fato mais importante foi o projeto conjunto entre o FASB e o IASB, que buscou criar um padrão comum de receita para as IFRSs e US Generally Accepted Accounting Principles (US GAAP) e culminou na emissão das IFRS 15 - Revenue from Contracts wtih Customers ((IFRS 2018a, pp. A789-A857), em vigor a partir de 2018. No Brasil, essa norma foi editada como CPC 47 - Receita de Contrato com Cliente.

A norma traz potenciais impactos nas demonstrações financeiras, pois sua aplicação precisa avaliar e definir: (i) se a entidade deverá reconhecer a receita pelo método Percentual de Completude (POC) ou se reconhece em um determinado momento; (ii) a possibilidade de o reconhecimento da receita ser acelerado ou diferido, exemplo: a existência de contraprestações de valor variável; (iii) incerteza relevante quanto a entrada de fluxo caixa, gerada por questões econômicas; e (iv) impactos tributários e em cláusulas de covenants.

Tem como princípio fundamental o reconhecimento da receita que represente a efetiva transferência de bens ou serviços prometidos aos clientes, em um valor que reflita a contraprestação que a entidade espera ter em troca desses bens ou serviços. Buscou-se, portanto, a criação de uma base comum de princípios e orientações para estabelecer uma estrutura abrangente para determinar quando reconhecer receita e o valor que deve ser reconhecido. 
De forma geral, os conceitos de receita e a definição do momento de seu reconhecimento adotados pelos CPC 00 e IFRS 15 / CPC 47 estão bastante alinhados com a teoria contábil (IUDÍCIBUS, 2015, p. 152; IUDÍCIBUS et al., 2013, p. 61; HENDRICKSEN; BREDA, 2012, p. 223; LOPES; MARTINS, 2017, p. 146; PYLE et al., 1980, p. 167; YAMAMOTO et al., 2011, p. 51) ao defini-los como aumentos nos benefícios econômicos durante o período contábil, sob a forma da entrada de recursos, do aumento de ativos ou diminuição de passivos, portanto, que resultam em aumentos do patrimônio líquido e que não sejam provenientes de aportes dos participantes do patrimônio. Numa visão mais restritiva, a IFRS 15 / CPC 47 acrescenta que para se considerar receita precisa ser renda oriunda do curso das atividades normais da entidade.

A Figura 2, contempla o diagrama o tratamento que deve ser dado em cada uma das situações em que o contrato com o cliente pode se enquadrar em relação a aplicação a IFRS / CPC 47.

Figura 2: Alcance do CPC 47

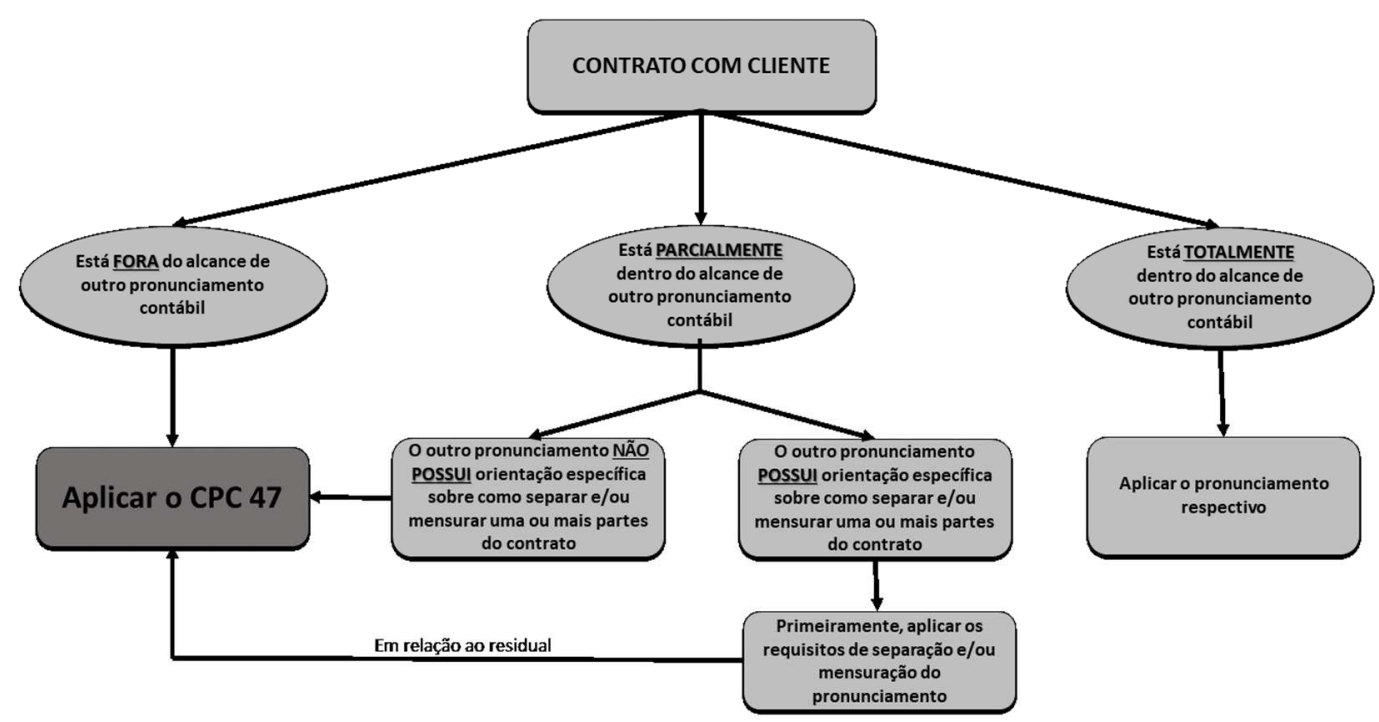

Fonte: Elaborado pelos autores com base no CPC 47, 2016.

Destaca-se que a IFRS 15 /CPC 47 define regras a serem seguidas para identificação, mensuração e reconhecimento de receitas de contrato com cliente, estruturadas em cinco etapas:

Etapa 1: Identificação do contrato com cliente

Etapa 2: Identificação de obrigação de desempenho

Etapa 3: Determinação do preço da transação

Etapa 4: Alocação do preço da transação a obrigações de desempenho

Etapa 5: Reconhecimento da receita com cliente

O fluxograma da Figura 3 demonstra a sequência da aplicação das cinco etapas. 
Figura 3: Fluxograma de aplicação do CPC 47

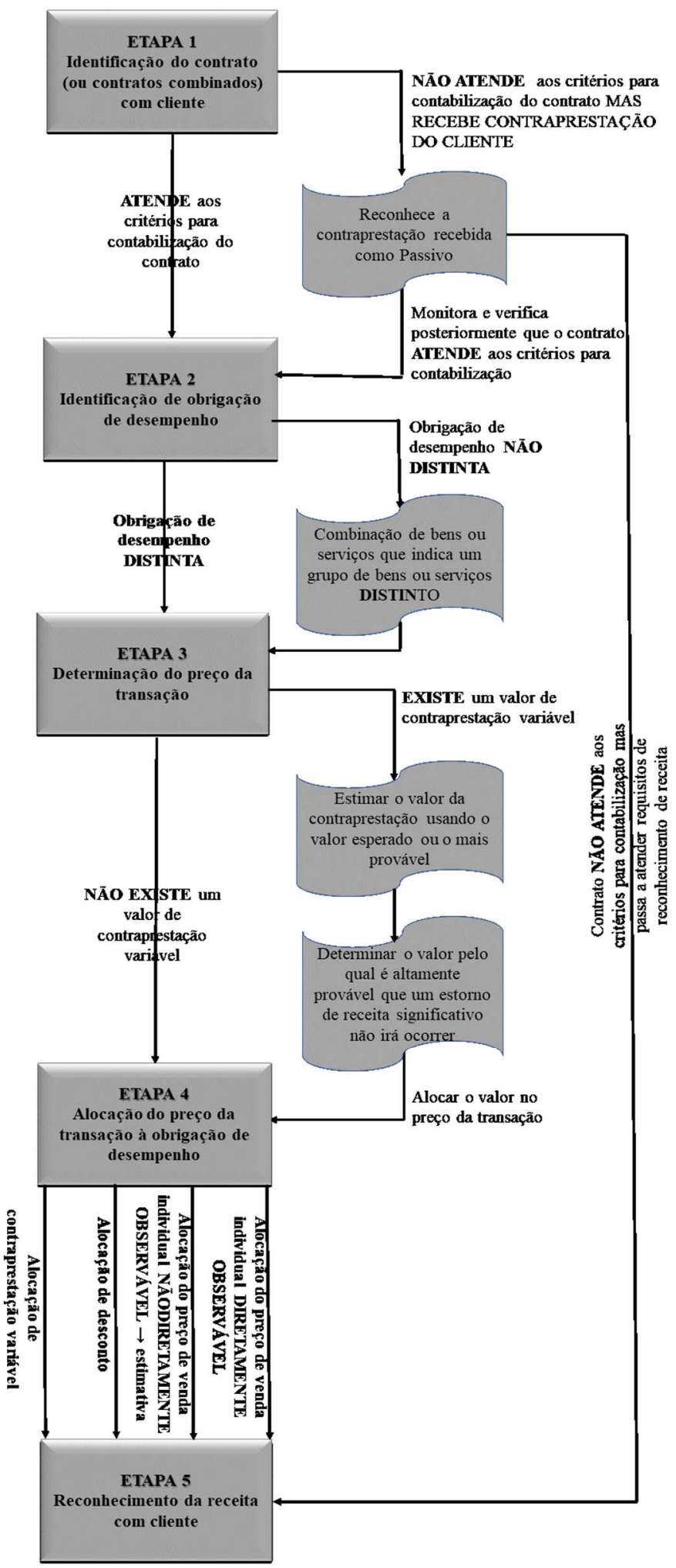

Fonte: Elaborado pelos autores a partir do CPC 47, 2016. 


\subsection{Perdas esperadas por redução ao valor recuperável de operação de crédito}

Quanto ao impairment, ou seja, o reconhecimento de perdas esperadas por redução ao valor recuperável de operação de crédito, a IFRS 15 / CPC 47 define que deve ser aplicada a IFRS 9 / CPC 48 - Instrumentos Financeiros, a qual faz com que as entidades se antecipem aos eventos de deterioração de crédito e apresentem informação útil que permita ao usuário a avaliação dos valores, época e incerteza dos fluxos de caixa futuros da entidade. A conta a receber de cliente se identifica como ativo financeiro por ser um direito presente e contratual de receber uma contraprestação, mesmo que esse valor venha a ser pago no futuro.

A IFRS 9 / CPC 48 introduziu nova classificação para os ativos financeiros, que deve se basear tanto no modelo de negócios da entidade para a gestão dos ativos financeiros quanto nas características de fluxo de caixa contratual do ativo financeiro. São três as classificações: (i) mensurado ao custo amortizado; (ii) mensurado ao valor justo por meio de outros resultados abrangentes, ou (iii) mensurado ao valor justo por meio do resultado.

Para determinar o critério de mensuração, o qual promove uma distinção clara para a adoção da mensuração pelo custo amortizado deve-se verificar a existência ou não de fluxos contratuais que representam somente principal e juros. Se sim, não tem a opção de aplicar o valor justo para eliminar descasamentos, classifica-se como custo amortizado. Se não, como valor justo por meio de outros resultados abrangentes. Se na origem se verifica que os fluxos contratuais não são representados somente por principal e juros, então, se enquadra como valor justo por meio do resultado.

Por meio dessa norma foi introduzida uma mudança importante: a perda de crédito deve ser reconhecida não só quando incorrida, calculada com base em eventos de inadimplência conhecidos na data do balanço, mas, também, quando esperada, calcada em estimativa que resulta de todos os eventos de inadimplência possíveis ao longo da vida esperada do ativo financeiro. Busca dar tempestividade ao reconhecimento contábil do seu efeito econômico e limitar ao máximo a possibilidade de gerenciamento de resultado.

Para as empresas de medicina diagnóstica, os investimentos em valores a receber (risco de crédito) representam uma parte significativa de seus ativos circulantes, exercendo, em consequência, importante influência em suas rentabilidades. Parte dos recebíveis não têm convertibilidade financeira, devendo ser estimada e registrada contabilmente, bem como ser reconhecida a sua perda efetiva quando esgotadas as alternativas de cobrança e recebimento.

Erros administrativos e técnicos podem gerar o não reconhecimento, por parte dos clientes, dos serviços diagnósticos realizados. Quando procedente, está caracterizada a "glosa", ou seja, o não pagamento, pela contraparte, de valores referentes a atendimentos, medicamentos ou materiais cobrados pelas empresas de medicina diagnóstica, a qual afeta a realização da receita. As glosas estão geralmente relacionadas a: (i) Questões operacionais, tais como: serviços prestados sem prévia autorização do planos de saúde, quando exigido; documentação inadequada; e incorreção nos valores cobrados; (ii) Questões comerciais, a exemplo cobrança com base em lista de preços desalinhada com negociação nova; e (iii) Questões técnicas, como a divergências de interpretação de requisições de exames.

Assim, entidades do segmento de medicina diagnóstica têm dois momentos específicos para a realização da baixa contábil (write-off) do recebível:

1. Duplicatas/boletos/cheques: De acordo com o Regulamento do Imposto de Renda - RIR (IN RFB $\left.n^{\circ} 1.700,2017\right)$ quando não liquidados, poderão ser baixados como perdas a partir do período de apuração no qual completarem seis meses (operações de valor individual de até $\mathrm{R} \$$ 15.000) ou cinco anos (demais operações) do vencimento do recebível.

2. Glosas de serviços: Quando o faturamento se dá e o cliente, a posteriori, questiona a pertinência dos serviços realizados e o prestador aceita a glosa. 


\title{
2.5. Divulgação
}

No final da década de trinta, Montgomery (1938 apud CHAMBERS, 1969, p. 524) descreveu contabilidade como "a linguagem das finanças", já demonstrando que a contabilidade serve como uma forma de linguagem entre a entidade e os usuários das informações contábilfinanceiras da entidade. Chambers (1969), sequencia explicitando o que o empresário quer saber da contabilidade:

\begin{abstract}
Um empresário não quer simplesmente saber que seus ativos são mais do que eram ontem; ele quer saber quanto mais. Ele não quer simplesmente saber que o rendimento do ano passado foi menor do que no ano anterior; ele quer saber quanto menos. Ele não quer simplesmente saber que o novo produto aumentará seu lucro; ele quer saber quanto. Assim, se a contabilidade é para ser o meio pelo qual ele é informado, a contabilidade deverá envolver mensuração e as proposições que que sejam representativas das mensurações feitas. (CHAMBERS, 1969, pp. 524-525)
\end{abstract}

Damodaran (2012, p. 57), reconhece a importância dos demonstrativos contábeis na avaliação de investimentos, ao concluir que "os demonstrativos financeiros continuam sendo a principal fonte de informação para a maioria dos investidores e analistas".

Assaf Neto (2003, p. 96) comenta a importância das notas explicativas às demonstrações contábeis, ressaltando que "vê-se que é compulsória a leitura atenta das notas explicativas antes de se efetuar qualquer análise financeira, dada a relevância das informações contidas".

Iudícibus (2017, p. 67), referindo-se às notas explicativas e outras evidenciações como informações que enriquecem os relatórios contábeis, destaca que "Tais evidenciações devem ser destacadas no sentido de auxiliar a compreensibilidade pelo usuário das referidas demonstrações, para que possa extrair as informações que lhe são úteis na tomada de decisão".

Para efeito de divulgação, a IFRS 15 / CPC 47, item 110, afirma que "o objetivo dos requisitos de divulgação consiste em que a entidade divulgue informações suficientes para permitir aos usuários de demonstrações contábeis compreender a natureza, o valor, a época e a incerteza de receitas e fluxos de caixa provenientes de contratos com clientes. [...]".

Para isso, define que as empresas devem divulgar informações qualitativas e quantitativas como: (i) receitas e perdas reconhecidas com contratos com cliente; (ii) desagregação de receitas reconhecidas em categorias que descrevam como a natureza, o valor, a época e a incerteza dos fluxos de caixa das receitas são afetados por fatores econômicos; (iii) saldos inicial e final de contratos com clientes, explicando quantitativa e qualitativamente alterações significativas nos saldos; (iv) obrigações de desempenho; (v) julgamentos, e as mudanças nos julgamentos, feitos ao aplicar a norma que afetem significativamente a determinação do valor e época das receitas provenientes de contratos com clientes.; (vi) determinação da época de satisfação de obrigação de desempenho; e (vii) determinação do preço da transação e dos valores alocados a obrigações de desempenho.

\subsection{Características operacionais do segmento de medicina diagnóstica}

O reconhecimento da receita deve satisfazer também a condição de que esses benefícios econômicos associados à transação fluirão para a entidade. Os serviços de medicina diagnóstica estão geralmente estruturados em dois ciclos: produção, que compreende as etapas de orientar o cliente antes do exame, passando pela coleta, transporte da amostra, realização do exame e disponibilização do laudo médico, e o financeiro, composto pelas etapas de faturamento, cobrança e recebimento ou baixa por perdas, conforme apresenta a Figura 4. 
Figura 4: Medicina diagnóstica - Ciclos de produção e financeiro de contrato com cliente

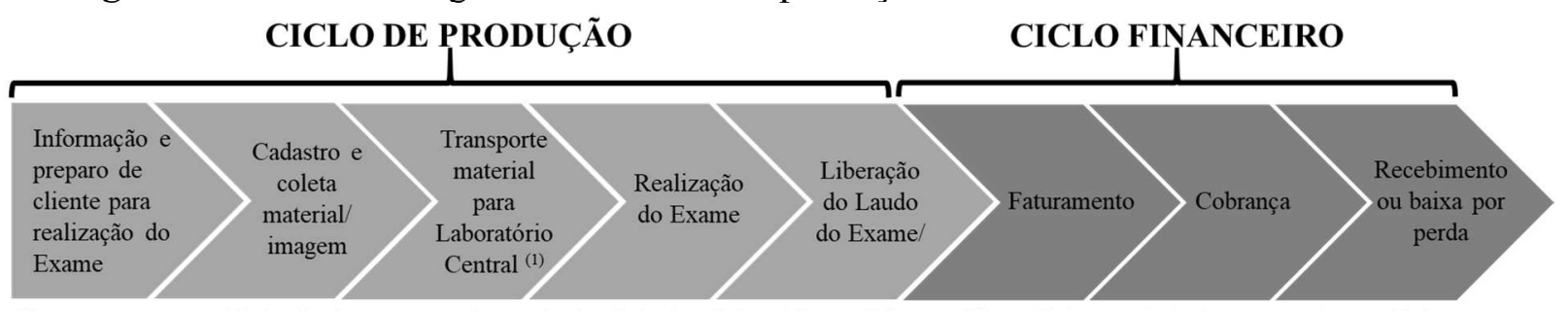

(1) Somente o material destinado a exames de patologia clínica/medicina laboratorial ou análises clínicas e citologia e anatomia patológica.

Fonte: Elaborado pelos autores.

A principal questão, portanto, é estabelecer o momento adequado do reconhecimento da receita. A título de exemplo, no segmento de medicina diagnóstica, quando se refere a plano de saúde, o usuário do serviço não é o cliente do laboratório, e sim, o cliente do convênio médico, e isto não configura, por si só, elemento suficiente para o reconhecimento da receita, visto que a formalística contratual precisa ser cumprida para que o direito de cobrança seja configurado.

\section{Procedimentos Metodológicos da Pesquisa}

Esta pesquisa caracteriza-se como exploratória quanto aos objetivos, documental como técnica de coleta de informações e evidências e qualitativa na abordagem do problema. Do ponto de vista dos objetivos e procedimentos técnicos, a pesquisa é exploratória, dado que não existem muitas informações sobre o tratamento contábil de receita de cliente no âmbito do segmento de medicina diagnóstica, carecendo uma maior proximidade da realidade do tema estudado. Segundo Matias-Pereira (2012, p. 88), a pesquisa exploratória "visa proporcionar maior familiaridade com o problema com o intuito de torná-lo explícito ou de construir hipóteses."

No que tange à técnica de coleta de informações, dados e evidências, a coleta de dados foi feita por meio de pesquisa documental, delimitada aos dados primários representados pelos contratos-padrão adotados com clientes pelas empresas objeto desta pesquisa (o acesso teve caráter confidencial) e pelas suas demonstrações contábeis obtidas no site das próprias empresas. Corrobora o pensamento de Martins e Theóphilo (2009, p. 55) "a pesquisa documental emprega fontes primárias, assim considerados os materiais compilados pelo próprio autor do trabalho, que ainda não foram objeto de análise, ou que ainda podem ser reelaborados de acordo com os propósitos da pesquisa."

Para a análise dos dados, foi utilizada a análise de conteúdo por meio de inferência, embasando-os nos pressupostos teóricos concebidos pelas IFRS quanto às bases para identificação, reconhecimento, mensuração e sua divulgação aos usuários das informações, tudo isso orientado pelas questões de pesquisa que necessitam ser respondidas. Alinha-se ao entendimento de Campos (2004, p. 613-614), “a análise de conteúdo não deve ser extremamente vinculada ao texto ou a técnica, num formalismo excessivo, que prejudique a criatividade e a capacidade intuitiva do pesquisador, por conseguinte, nem tão subjetiva, levando-se a impor as suas próprias ideias ou valores, no qual o texto passe a funcionar meramente como confirmador dessas."

Quanto à forma de abordagem do problema, trata-se de uma pesquisa qualitativa, pois busca descrever, compreender e explicar a realidade do tratamento de receita de cliente por empresas do segmento de medicina diagnóstica selecionadas para a pesquisa, por intermédio do estudo dos dados obtidos e à luz da aderência regulatória, consignada na IFRS. Como conceitua Chizzotti (2001) entende que a pesquisa qualitativa:

Parte do fundamento de que há uma relação dinâmica entre o mundo real e o sujeito, uma interdependência viva entre o sujeito e o objeto, um vínculo indissociável entre o mundo objetivo e a subjetividade do sujeito. O conhecimento não se reduz a um rol de dados 
isolados, conectados por uma teoria explicativa; o sujeito-observador é parte integrante do processo de conhecimento e interpreta os fenômenos, atribuindo-lhes um significado. O objeto não é um dado inerte e neutro; está possuído de significado e relações que sujeitos concretos criam em suas ações. (CHIZZOTTI, 2001, p. 79)

A pesquisa considerou todas as empresas do Brasil de medicina diagnóstica de capital aberto e com ações negociadas na B3 em junho de 2018, aos contratos com clientes adotados por essas empresas para cada mercado de atuação/tipo de cliente e suas demonstrações contábeis das datas-base de 31 de dezembro de 2017 e 30 de junho de 2018. A Tabela 1 mostra as empresas selecionadas.

O percurso metodológico consistiu em analisar os modelos de contratos que compõem os principais tipos de serviços de medicina diagnóstica quanto a aderência à IFRS 15 / CPC 47, avaliados os aspectos relativos à redução do valor recuperável e desreconhecimento de recebíveis, comparando os critérios de PECLD e baixas por perdas por glosas e, por fim, verificado se as informações qualitativas e quantitativas de receita e contas a receber de clientes divulgadas atendem aos critérios de disclosure previsto nas IFRS.

Tabela 1: Medicina diagnóstica - maiores empresas de capital aberto no Brasil

\begin{tabular}{|c|c|c|c|c|}
\hline Empresa & $\begin{array}{l}\text { Mercados de atuação/ } \\
\text { clientes }\end{array}$ & $\begin{array}{c}\text { Ativo } \\
\text { Total } \\
\text { 31/12/2017 } \\
\text { (R\$ mil) }\end{array}$ & $\begin{array}{l}\text { Patrimônio } \\
\text { Líquido } \\
\text { 31/12/2017 } \\
\text { (R\$ mil) }\end{array}$ & $\begin{array}{c}\text { Receita de } \\
\text { Serviços } \\
2017 \\
\text { (R\$ mil) }\end{array}$ \\
\hline $\begin{array}{l}\text { Centro de Imagem Diagnósticos S/A } \\
\text { (ALLIAR, 2018) }\end{array}$ & $\begin{array}{l}\text { Planos de saúde; hospitais; } \\
\text { governo; clientes particulares. }\end{array}$ & 2.284 .985 & 1.270 .256 & 1.077 .876 \\
\hline $\begin{array}{l}\text { Diagnósticos da América S/A } \\
\text { (DASA, 2018) }\end{array}$ & $\begin{array}{l}\text { Planos de saúde; hospitais; } \\
\text { apoio a laboratórios; governo; } \\
\text { particulares e pesquisa clínica. }\end{array}$ & 6.246 .487 & 3.319 .949 & 3.399 .308 \\
\hline $\begin{array}{l}\text { Fleury S/A } \\
\text { (FLEURY, 2018) }\end{array}$ & $\begin{array}{l}\text { Planos de saúde; hospitais; } \\
\text { apoio a r laboratórios; } \\
\text { particulares e pesquisa clínica. }\end{array}$ & 3.527 .332 & 1.413 .608 & 2.383 .012 \\
\hline $\begin{array}{l}\text { Instituto Hermes Pardini S/A } \\
\text { (IHP, 2018) }\end{array}$ & $\begin{array}{l}\text { Planos de saúde; hospitais; } \\
\text { apoio a laboratórios; governo e } \\
\text { particulares. }\end{array}$ & 1.152 .628 & 537.596 & 1.117 .038 \\
\hline
\end{tabular}

Fonte: Elaborado pelo autor com base nas demonstrações contábeis da Alliar (2018); Dasa (2018); Fleury (2018); IHP (2018).

A pesquisa foi estruturada em 3 (três) dimensões, conforme apresenta a Figura 5. As dimensões constantes da Figura 5 são assim descritas:

- Dimensão Objeto - numa visão tridimensional, buscou identificar e relacionar: (i) os tomadores dos serviços de medicina diagnóstica e seus respectivos contratos; (ii) o Ciclo de Receita de Cliente e suas fases (atendimento/valores a faturar, o Contas a Receber, a cobrança, perdas com crédito e aspectos da recuperação de crédito); e (iii) os registros do ciclo de receita (atendimento/faturamento, a contabilização da receita de cliente, os procedimentos de baixa e requerimentos de divulgação na demonstrações financeiras). Assim, todos os aspectos do objeto em estudo foram contemplados e inter-relacionados;

- Dimensão Teste - identificou os principais tipos de contratos celebrados com clientes e as demonstrações financeiras e confrontou (teste de aderência) com as cinco fases da IFRS 15 / CPC 47 a serem seguidas para identificação, mensuração e reconhecimento de receitas de contrato com cliente, bem como verificou a aderência em relação à IFRS 9 / CPC 48 quanto à PECLD, desreconhecimento de receita e baixa (write off) de créditos. Também verificou aspectos tributários aplicáveis à receita de contrato de 
cliente e aspectos de divulgação precursionados pelo Framework / CPC 00 (R1) e IAS 1 / CPC 26 (R1); e

Figura 5: Estrutura da Pesquisa

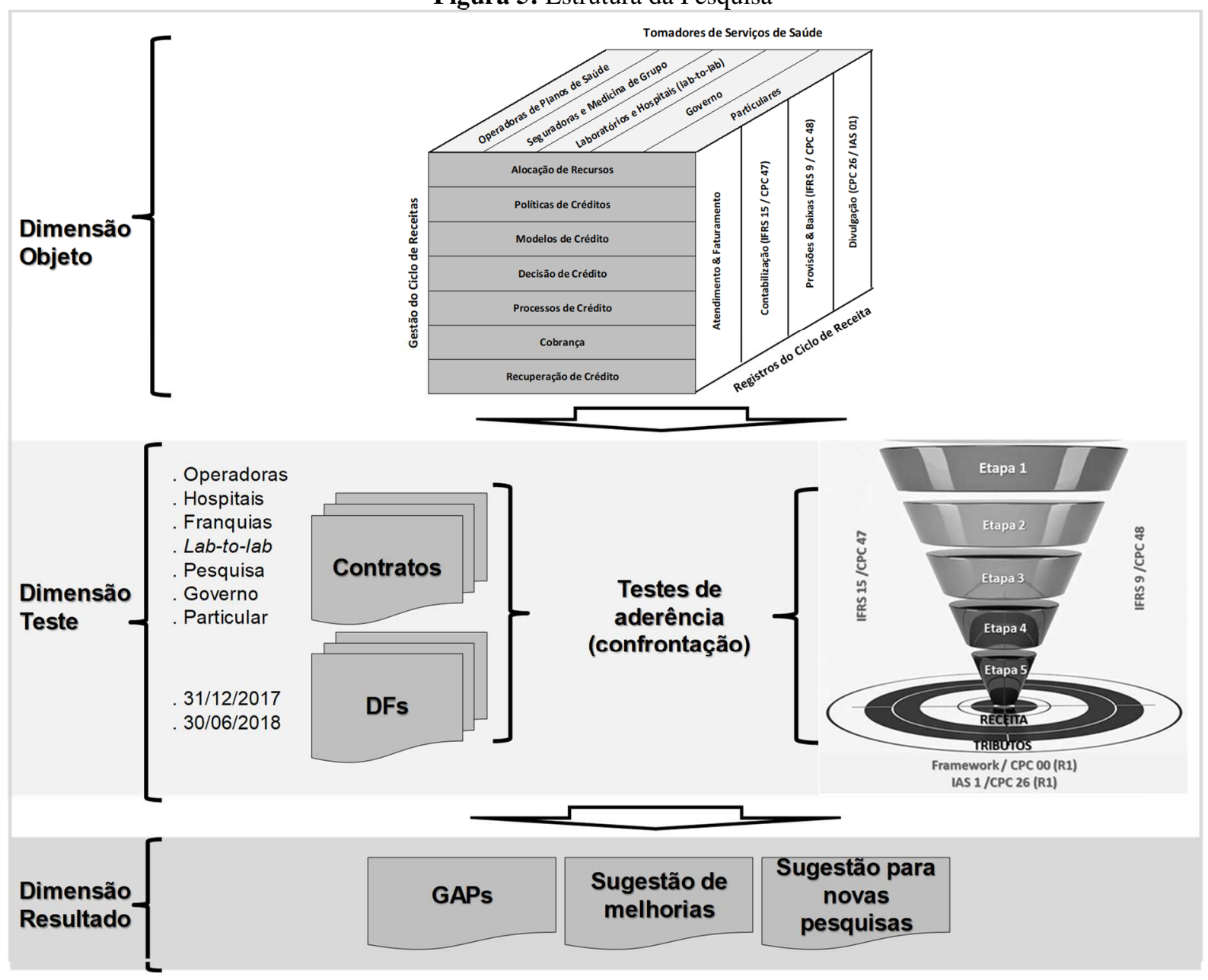

Fonte: Elaborado pelos autores.

- Dimensão Resultado -analisou a aderência das empresas às normas e os gaps respectivos, bem como identificou e sugeriu oportunidade de melhorias e temática para novas pesquisas.

\section{Apresentação e Análise do Resultado da Pesquisa}

\subsection{Identificação, mensuração e reconhecimento de receita com cliente}

Conforme a regra geral, observa-se que as entidades de medicina diagnóstica prestam serviços para os planos de saúde, hospitalar, governo, apoio a laboratórios, pesquisa clínica e a clientes particulares.

Observou-se que foram aplicadas as 5 (cinco) etapas da IFRS 15 / CPC 47 aos modelos de contratos constantes da Figura 6, agrupados quando similares. 
Figura 6: Medicina diagnóstica - Tipos de contrato

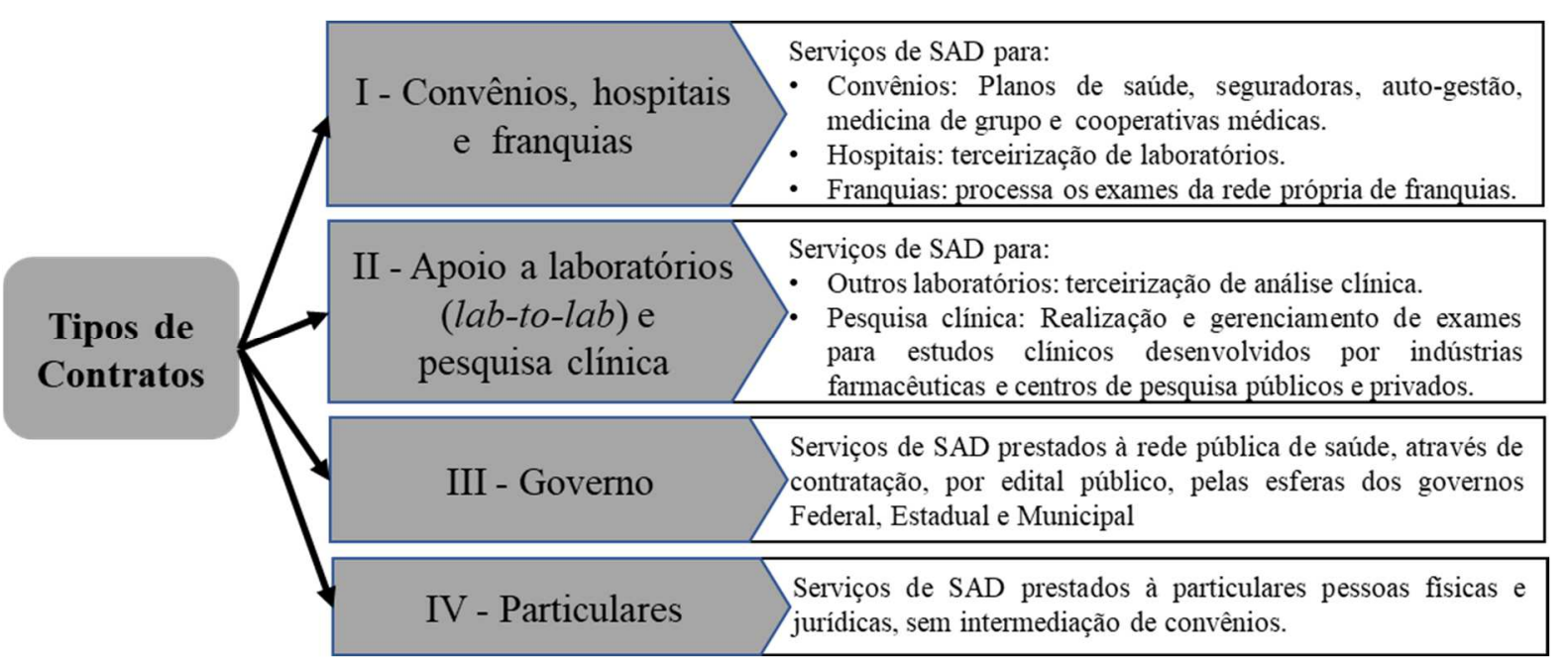

Fonte: Elaborado pelos autores com base nos contratos-padrão das empresas da amostra.

A verificação de aderência desses contratos à IFRS 15 /CPC 47 resultou em cinco etapas:

Etapa 1: Identificação do Contrato com o Cliente: Constatado que os contratos celebrados são formais, têm como objetivo prestar serviços de apoio diagnóstico e dispõem de cláusulas assecuratórias e claras (Quadro 1).

Quadro 1: Medicina diagnóstica - identificação do contrato com cliente

\begin{tabular}{|c|c|c|c|c|}
\hline Requisitos & 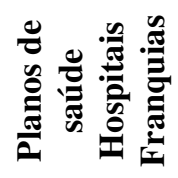 & 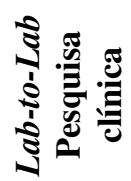 & 总 & 营 \\
\hline Objeto e local de realização & Sim & Sim & Sim & Sim \\
\hline Natureza e especificação dos serviços contratados & $\operatorname{Sim}$ & Sim & Sim & Sim \\
\hline Cobertura e critérios para autorização de cobertura dos serviços & $\operatorname{Sim}$ & Não & Sim & Não \\
\hline Beneficiários & $\operatorname{Sim}$ & Não & Não & Não \\
\hline Remuneração, critérios e periodicidade de reajustes de preços & $\operatorname{Sim}$ & Sim & Sim & Sim \\
\hline Prazos de faturamento e pagamento e forma de cobrança & Sim & Sim & Sim & Não \\
\hline Critérios e prazos para discussão de glosas & Sim & Não & Sim & Não \\
\hline Prazo de vigência & Sim & Sim & Sim & Não \\
\hline Direitos e obrigações das partes definidos & $\mathrm{Sim}$ & Sim & Sim & Sim \\
\hline
\end{tabular}

Fonte: Elaborado pelos autores com base nos contratos analisados.

À exceção daqueles celebrados com entes governamentais e clientes particulares, os contratos são de prazo indeterminado (têm premissas e forma de encerramento por qualquer das partes) ou são de prazo determinado e com cláusula de renovação periódica.

Apenas o contrato celebrado com cliente particular não é formal. Vincula-se a uma guia de realização de exames que espelha uma solicitação expedida por profissional médico. Nessa guia constam os preços avençados, as datas de disponibilização dos resultados dos exames e o aceite do cliente em relação aos procedimentos técnicos e termos administrativos e financeiros.

Etapa 2 - Identificação das Obrigações de Desempenho: Os contratos analisados expressam a obrigação de prestar os serviços de diagnóstico diretamente aos contratantes ou aos beneficiários do plano de saúde ou usuários do serviço público de saúde. Para o cumprimento dessa obrigação 
de desempenho, os contratos contemplam requisitos a exemplo de qualificação do corpo técnico do prestador; procedimentos administrativos; e geração de laudos técnicos.

Etapa 3 - Determinação do preço da transação: Para análise da determinação de preço da transação foram considerados, em aderência ao recomendado pela norma, os efeitos dos itens:

a) Contraprestação variável: Todos os contratos adotam o modelo de remuneração por procedimento (exame ou pacotes/conjunto de serviços para procedimentos padronizados), de forma que não há variabilidade de preços no contexto do que é estabelecido pela IFRS 15 /CPC 47. Há contratos que estipulam preços diferenciados por volume de exames, diminuindo o preço unitário em função de faixas crescentes de volumes, num equilíbrio volume-preço. Essa situação não caracteriza variabilidade de preço, pois este é previamente contratado e conhecido para qualquer condição de volume.

A glosa poderia ser entendida como geradora de variabilidade de preço e caracterizar contraprestação variável, por afetar a receita, porém, a glosa cancela receita, mas não diminui preço unitário. O ajuste no faturamento é feito com base nos preços contratados para os serviços rejeitados. A rigor, essa receita não deveria ter sido contabilizada, visto que não atendeu às premissas contratuais, situação só detectada posteriormente ao faturamento.

Há contratos com governo que estipulam bandas mínima e máxima de quantidade de exames a serem prestado em um período de tempo. Se menos exames prestados, diminui-se o valor total da contraprestação paga pelo contratante. Se mais exames, paga-se mais. Essa situação não caracteriza variabilidade de preço, pois este é previamente contratado e conhecido para qualquer condição de volume. $\mathrm{O}$ valor total varia em função de alterações nas quantidades de exames, e não nos preços.

Diante disto, os demais itens da IFRS 15 / CPC 47 previstos para avaliar essa etapa (itens 52 a 55 e 59) deixaram de ser aplicados aos contratos analisados.

b) Restrição de estimativas de contraprestação variável: Dada a inexistência de contraprestação variável nos contratos, restrição de estimativas perde aplicabilidade de análise.

c) Existência de componentes de financiamento significativo no contrato: Os prazos para a prestação de contas a partir da realização do exame e o de vencimento da obrigação de pagamento pelo contratante são curtos, até 60 dias, exceto em relação ao cliente particular, quando o pagamento dos exames se dá em espécie, cheque, cartão de débito ou por meio de cartão de crédito, com prazo de parcelamento inferior a 12 meses. Não há, portanto, um componente financeiro a ser considerado nessa análise.

d) Contraprestação não monetária e Contraprestação a pagar ao cliente: Não aplicável. O serviço prestado em função de contratos analisados é monetário, em dinheiro e não prevê contraprestação para o cliente, monetária ou não.

Portanto, o preço da transação a ser considerado nos contratos analisados é justamente o valor contratualmente estabelecido, sem variações.

Etapa 4 - Determinação dos custos do contrato: A entidade deve reconhecer como ativo os custos incrementais para obtenção de contrato com cliente, se a entidade espera recuperar esses custos. Essa prerrogativa não é prática nos contratos analisados.

Etapa 5 - Alocar os preços das transações às obrigações de desempenho: Não aplicável aos contratos com apenas uma obrigação de desempenho, característica dos casos aqui analisados.

Considerando a aplicação das 5 Etapas da IFRS 15 / CPC 47 aos contratos analisados e a verificação de que todas as relações contratuais com clientes indicam a existência de uma única 
obrigação de desempenho, que é a prestação de serviço de diagnóstico, a obrigação de desempenho entende-se atendida, conforme apresenta o Quadro 2, e, assim, é possível o reconhecimento da receita.

Quadro 2: Tipologia de contratos de cliente e análise de reconhecimento de receita

\begin{tabular}{|l|c|c|c|c|c|}
\hline \multirow{2}{*}{$\begin{array}{c}\text { IFRS 15 / } \\
\text { CPC 47 }\end{array}$} & $\begin{array}{c}\text { Etapa 1 } \\
\text { Identifica- } \\
\text { ção do de } \\
\text { contrato } \\
\text { com o } \\
\text { cliente }\end{array}$ & $\begin{array}{c}\text { Etapa 2 } \\
\text { Identificação } \\
\text { das } \\
\text { obrigações de } \\
\text { desempenho }\end{array}$ & $\begin{array}{c}\text { Etapa 3 } \\
\text { Determinação } \\
\text { do preço da } \\
\text { transação }\end{array}$ & $\begin{array}{c}\text { Determinação } \\
\text { dos custos do } \\
\text { contrato de } \\
\text { desempenho }\end{array}$ & $\begin{array}{c}\text { Alocar o } \\
\text { preço das } \\
\text { transações às } \\
\text { obrigações de } \\
\text { desempenho }\end{array}$ \\
\hline $\begin{array}{l}\text { Planos de saúde, } \\
\text { hospitais e franquias }\end{array}$ & Atende & Atende & Atende & Não aplicável & Não aplicável \\
\hline $\begin{array}{l}\text { Apoio a laboratórios } \\
\text { e pesquisa clínica }\end{array}$ & Atende & Atende & Atende & Não aplicável & Não aplicável \\
\hline Governo & Atende & Atende & Atende & Não aplicável & Não aplicável \\
\hline Particulares & Atende & Atende & Atende & Não aplicável & Não aplicável \\
\hline
\end{tabular}

Fonte: Elaborado pelos autores com base nos contratos analisados.

Corroborando o resultado da análise de contratos, todas as empresas avaliadas concluíram que seus contratos atendem as condições para adoção da IFRS 15 / CPC 47.

\subsection{Apresentação do contrato no balanço patrimonial}

A entidade deve apresentar o contrato no balanço patrimonial quando tiver executado o desempenho. Neste contexto, o segmento de medicina diagnóstica tem a característica de transferir o serviço ao cliente antes do recebimento da contraprestação, exceto no caso de clientes particulares (pessoa física ou jurídica) com pagamento em espécie, quando a entidade executa o desempenho, no extremo, poucos dias após o recebimento.

As empresas analisadas reconhecem a receita quando: (i) o valor pode ser mensurado com segurança; (ii) é provável que benefícios econômicos futuros fluirão para a entidade; e (iii) quando critérios específicos tiverem sido atendidos para cada uma das atividades da entidade, conforme contratos celebrados com clientes; e (iv) com base nos serviços realizados até a data do balanço. Nesse momento, os serviços prestados e ainda não faturados são registrados como "receita a faturar" e compõe o saldo do contas a receber.

\subsection{Redução do valor recuperável}

O CPC 47 (2016, p. 23), estabelece que a entidade deve avaliar um ativo de contrato quanto à redução do valor recuperável, definido que o tratamento contábil a ser dado esteja de acordo com o pronunciamento IFRS 9 / CPC 48. Para efeito de tratamento dos serviços de medicina diagnóstica, a avaliação foi feita em relação aos seguintes tópicos da norma:

a) Identificação de ativos financeiros: As contas a receber de clientes se classificam como instrumento financeiro para efeito das disposições da IFRS 9 / CPC 48, ou seja, os recebíveis de crédito são ativos financeiros não derivativos com pagamentos fixos ou determináveis mesmo se pagos no futuro.

b) Classificação dos ativos financeiros: O modelo de negócio, suas características e a classificação de cada tipo de contrato, leva a concluir que as entidades de serviços de medicina diagnóstica atendem os requisitos de mensuração ao custo amortizado por manter recebíveis 
com o fim de receber fluxos de caixa contratuais atrelados ao pagamento de principal e, quando houver, juros por atraso.

Há a possibilidade de venda de carteira de recebíveis e de antecipação de recebíveis de cartões de crédito com as próprias operadoras de cartão. Conforme o CPC 48 item B4.1.3, "o modelo de negócios da entidade pode ser manter ativos financeiros para receber fluxos de caixa contratuais, mesmo quando vendas de ativos financeiros ocorram ou que seja esperado que ocorram no futuro". Assim, não há risco de reclassificação do modelo de negócios de serviços de medicina diagnóstica de custo amortizado para valor justo por meio de outros resultados abrangentes.

c) Desreconhecimento de ativos financeiros: A análise nesse contexto foi feita em relação à possibilidade de venda de carteira de crédito e de antecipação de recebíveis vir a caracterizar o desreconhecimento do ativo financeiro.

A venda de carteira de crédito e antecipação de recebíveis de cartão de crédito se enquadram na alínea (b) do item 3.2.3 do CPC 48, em que a transferência de ativos se dá pelo pagamento, pela empresa adquirente, do valor principal deduzido de uma taxa de desconto previamente negociada. No segmento de medicina diagnóstica as vendas/antecipações se dão sem coobrigação, ou seja, há a transferência, sem direito de regresso, dos direitos contratuais de receber os fluxos de caixa futuros dos ativos cedidos.

O desreconhecimento do ativo, neste caso, implica na sua baixa quando do pagamento, pelo cessionário, do valor acordado. Neste ato, a diferença apurada entre o valor contábil do ativo cedido e o valor da contraprestação paga pelo cessionário é reconhecida no resultado contábil pela entidade de serviços de medicina diagnóstica.

Nenhum risco ou benefício da propriedade do ativo fica com a entidade cedente, de forma que essa caracterização descarta a análise de atender à condição de pass through dos fluxos de caixa líquidos futuros associados ao ativo financeiro.

d) Redução ao valor recuperável: Com a mudança para abrigar na provisão as perdas esperadas, em uma análise prospectiva do risco de crédito do recebível ao longo de seu prazo de duração as entidades de medicina diagnóstica precisam olhar para a perda histórica e constituir, no momento do reconhecimento da receita respectiva e sobre a mesma, uma provisão para fazer face ao potencial de perda futura. Nesse segmento, a redução ao valor recuperável se dá por meio das provisões a seguir, as quais são ajustadas periodicamente ao dimensionamento do risco:

(i) Provisão para perdas com glosas - Mesmo após o faturamento clientes glosam serviços/exames. Por não se tratar de inadimplência, mas de serviços sub judice e por historicamente não se recuperar todo o valor faturado, é constituída uma provisão para fazer face ao potencial de perdas com glosas;

(ii) Provisão estimada para créditos em liquidação duvidosa (PECLD) - constituída sobre duplicatas emitidas e sobre cheques recebidos para fazer face às perdas por decorrência da inadimplência incorrida e perda esperada em função do histórico de perdas.

O Quadro 3 compara os critérios de provisionamento divulgados pelas empresas, demonstrando que não há uniformidade de tratamento em relação às faixas de vencimento de recebíveis e nem no que concerne aos percentuais de provisão por faixa de vencimento, prejudicando a comparabilidade de performance em relação à própria entidade (evolução histórica) e também em elação às empresas do mercado em que atua. 


\begin{tabular}{|c|c|c|}
\hline \multicolumn{3}{|c|}{ Quadro 3: Medicina diagnóstica - critérios de provisionamento } \\
\hline EMPRESA & $\begin{array}{l}\text { CRITÉRIO DE PROVISIONAMENTO INFORMADO PELA } \\
\text { EMPRESA }\end{array}$ & OBSERVAÇÕES \\
\hline ALLIAR & $\begin{array}{l}\text { No ato do reconhecimento da receita provisiona perdas com glosas } \\
\text { com base na expectativa de perdas. } \\
\text { A constituição da PECLD segue três critérios: i) } 50 \% \text { do saldo em } \\
\text { aberto entre } 180 \text { e } 360 \text { dias e } 85 \% \text { do saldo em aberto acima de } 360 \\
\text { dias; ii) } 100 \% \text { do saldo de clientes que possuem algum tipo de } \\
\text { discussão judicial; iii) análise individual de eventos extraordinários. }\end{array}$ & $\begin{array}{l}\text { Não informou o } \\
\text { percentual de perda } \\
\text { histórica com glosas e } \\
\text { créditos duvidosos. }\end{array}$ \\
\hline DASA & $\begin{array}{l}\text { Aplica régua de provisionamento e constitui provisão para perdas } \\
\text { sobre exames a faturar, para duplicatas a vencer e para as vencidas } \\
\text { há até } 90 \text { dias. Os atendimentos não faturados em até } 120 \text { dias são } \\
\text { baixados contabilmente. Adota o critério de provisionar em } 100 \% \\
\text { os cheques de clientes devolvidos por insuficiência de fundos. }\end{array}$ & $\begin{array}{l}\text { Não divulgou os } \\
\text { percentuais de provisão e } \\
\text { respectivos valores por } \\
\text { faixa de vencimento. }\end{array}$ \\
\hline FLEURY & $\begin{array}{l}\text { Estima PECLD registrada de acordo com a média histórica de } \\
\text { negociação, confissão de dívida com parcelas em atraso e } \\
\text { negociação com reduzida probabilidade de sucesso. } \\
\text { Estima glosas com base em análises históricas e tendências } \\
\text { comerciais, sobre a receita gerada, faturada ou não. }\end{array}$ & $\begin{array}{l}\text { Não informou claramente } \\
\text { o critério de } \\
\text { provisionamento por } \\
\text { faixa de vencimento. }\end{array}$ \\
\hline IHP & $\begin{array}{l}\text { Constitui provisão de } 100 \% \text { para perdas de serviços executados a } \\
\text { faturar que a entidade entende não ser passível de recuperação. } \\
\text { Constitui provisão de } 100 \% \text { para créditos de liquidação duvidosa } \\
\text { para os recebíveis vencidos há mais de } 120 \text { dias. }\end{array}$ & $\begin{array}{l}\text { Não demostrou provisão } \\
\text { sobre créditos a faturar e } \\
\text { nem sobre duplicatas a } \\
\text { vencer e duplicatas } \\
\text { vencidas até } 120 \text { dias. }\end{array}$ \\
\hline
\end{tabular}

Fonte: Elaborada pelo autor com base nas demonstrações contábeis da Alliar (2018); Dasa (2018); Fleury (2018); IHP (2018).

Nas demonstrações contábeis de 30 de junho de 2018, representadas na Tabela 2, se verificou diversidade de modelos utilizados para a divulgação de saldo da carteira de recebíveis, da PECLD e da provisão de perdas sobre valores a faturar. Além das faixas de vencimento divulgadas não serem uniformes entre empresas, os percentuais de provisão, quando divulgados, não permitiram o recálculo para se chegar ao valor total da provisão registrada.

Tabela 2: PECLD

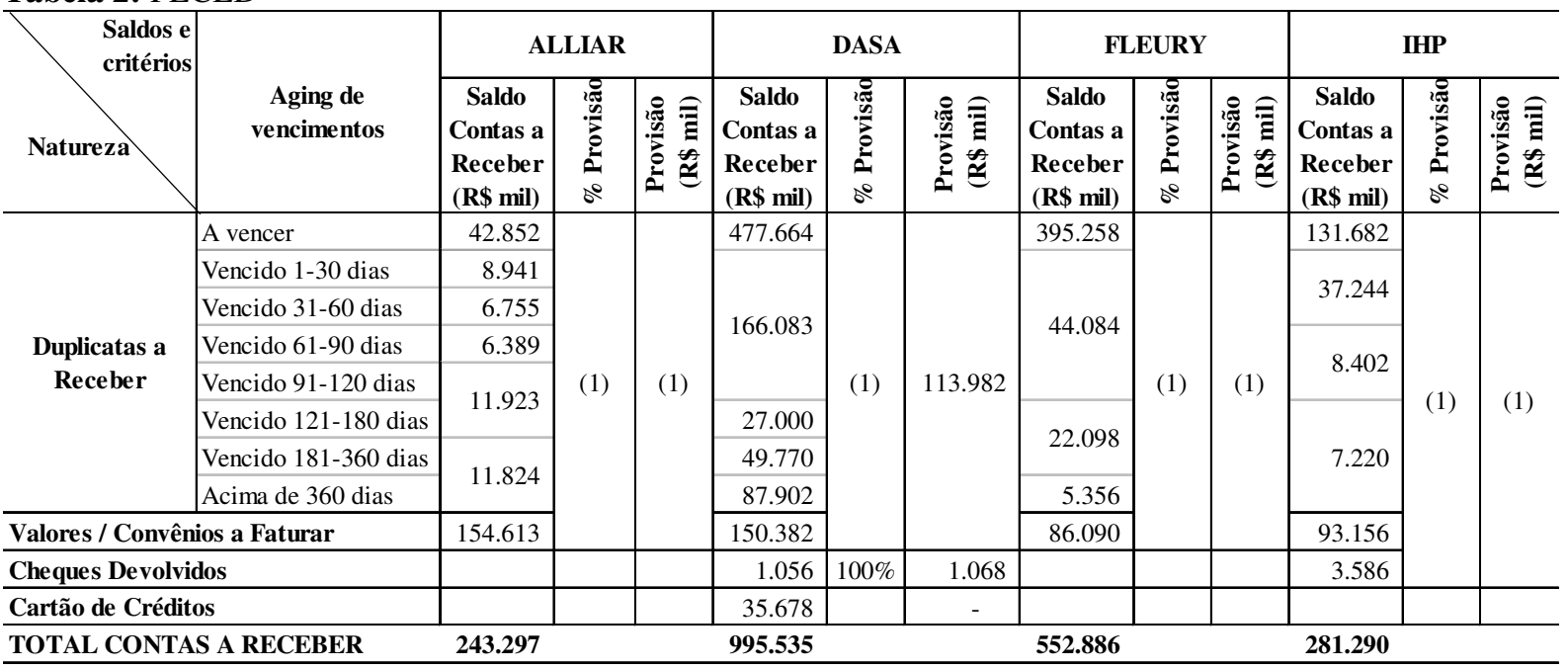

(1) Não individualizado por faixa de vencimento.

Fonte: Elaborada pelo autor com base nas demonstrações contábeis da Alliar (2018); Dasa (2018); Fleury (2018); IHP (2018).

\subsection{Baixa e recuperação}

À luz do CPC 48, a baixa (write-off) constitui evento de desreconhecimento de receita. A entidade deve reduzir diretamente o valor contábil bruto do contas a receber quando não tiver 
expectativas razoáveis de recuperar o recebível. Na data-base 30 de junho de 2018 apenas a ALLIAR declarou prazo para baixa definitiva de duplicatas/cheques a receber, enquanto que a DASA informou o prazo que adota para baixa definitiva de valores a faturar (Quadro 4).

Quadro 4: Prazos para baixa (write-off) de recebíveis

\begin{tabular}{|l|c|c|c|c|}
\hline \multirow{2}{*}{ Entidade } & \multicolumn{2}{c|}{$\begin{array}{c}\text { Valores a Faturar } \\
\text { Prazo para baixa (write-off) }\end{array}$} & $\begin{array}{c}\text { Duplicatas/cheques a Receber } \\
\text { Prazo para baixa (write-off) }\end{array}$ \\
\cline { 2 - 5 } & $\mathbf{3 1 / 1 2 / 2 0 1 7}$ & $\mathbf{3 0 / 0 6 / 2 0 1 8}$ & $\mathbf{3 1 / 1 2 / 2 0 1 7}$ & $\mathbf{3 0 / 0 6 / 2 0 1 8}$ \\
\hline ALLIAR & Não declarado & Não declarado & 360 dias & 360 dias \\
\hline DASA & 120 dias & 120 dias & 720 dias & Não declarado \\
\hline FLEURY & Não declarado & Não declarado & Não declarado & Não declarado \\
\hline IHP & Não declarado & Não declarado & Não declarado & Não declarado \\
\hline
\end{tabular}

Fonte: Elaborada pelo autor com base nas demonstrações contábeis da Alliar (2018); Dasa (2018); Fleury (2018); IHP (2018).

\subsection{Padronização dos registros contábeis}

Com base nas práticas adotadas pelas empresas analisadas e na regulamentação aplicável, os autores padronizaram o esquema de registro contábil, como pode ser visualizado na Figura 7 , em que destacam, à cada atividade/evento do ciclo de receita com cliente, as respectivas partidas contábeis.

Figura7: Segmento de medicina diagnóstica - ciclo de receita de cliente e fluxo contábil

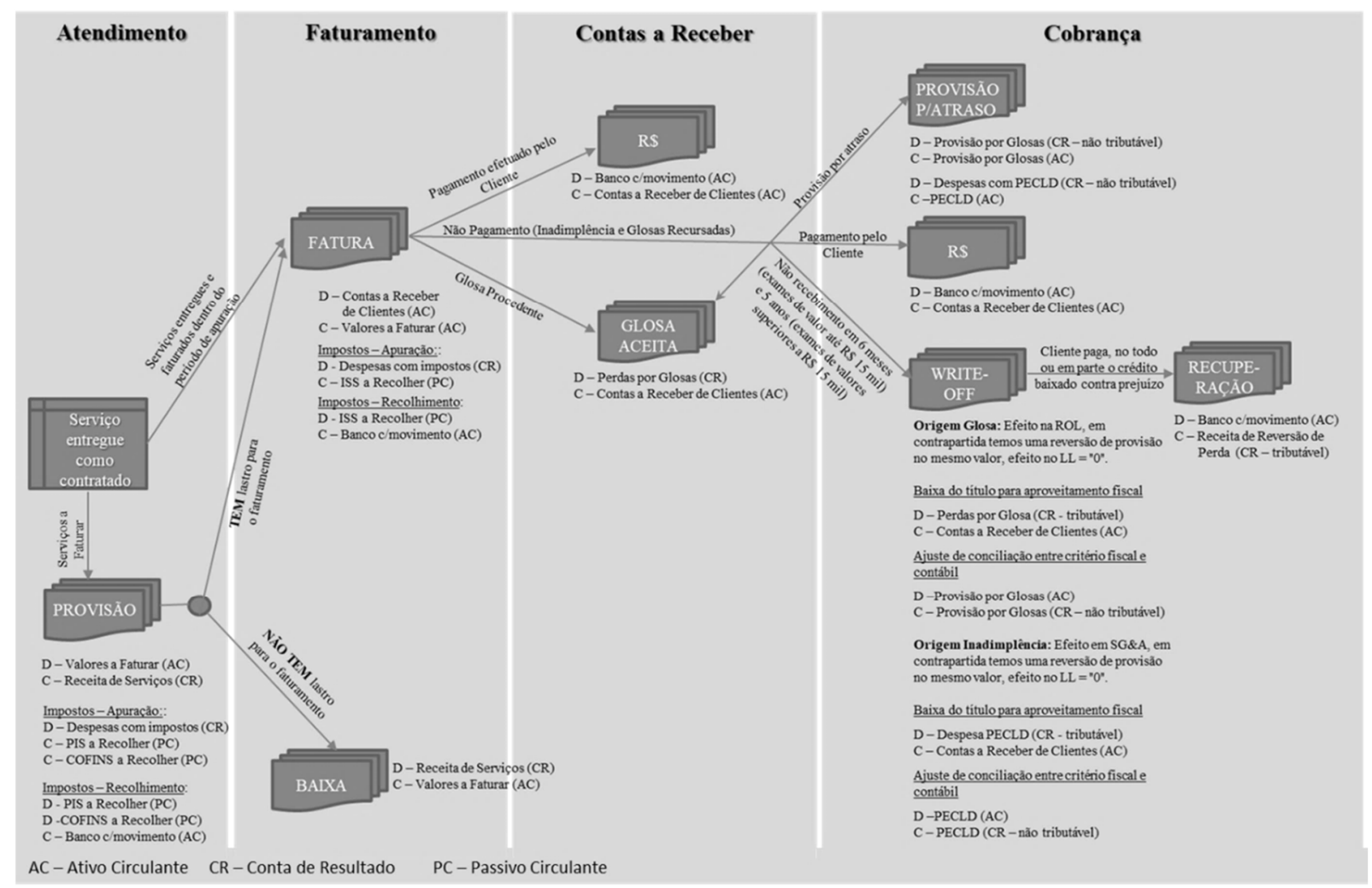

Fonte: Elaborada pelo autor baseado em sua experiência no setor de medicina diagnóstica e nas demonstrações contábeis da Alliar (2018); Dasa (2018); Fleury (2018); IHP (2018).

\subsection{Divulgações}

No geral, as entidades analisadas não estão aderentes aos requisitos da IFRS 15 / CPC 47 sobre divulgação de receita de clientes. Informações consideradas importantes para um melhor 
entendimento das receitas e suas movimentações não são divulgadas ou são de maneira incompleta. O Quadro 5 destaca essas inconformidades.

Quadro 5: Notas Explicativas sobre receita de cliente - comparativo

\begin{tabular}{|c|c|c|c|c|}
\hline Divulgação em Notas Explicativas & ALLIAR & DASA & FLEURY & IHP \\
\hline $\begin{array}{l}\text { Composição da carteira de recebíveis } \\
\text { por faixa de vencimento }\end{array}$ & $\begin{array}{l}\text { A vencer } \\
\text { Vencidos: } \\
1 \text { a } 30 \mathrm{dd} . \\
31 \text { a } 60 \mathrm{dd} . \\
61 \text { a } 90 \mathrm{dd} . \\
91 \text { a } 180 \mathrm{dd} . \\
\text { > } 180 \text { dias. }\end{array}$ & $\begin{array}{c}\text { A vencer } \\
\text { Vencidos: } \\
1 \text { a } 120 \mathrm{dd} . \\
121 \text { a } 180 \mathrm{dd} . \\
181 \text { a } 360 \mathrm{dd} . \\
\text { > } 360 \mathrm{dd} .\end{array}$ & $\begin{array}{l}\text { A vencer } \\
\text { Vencidos: } \\
1 \text { a } 120 \mathrm{dd} \text {. } \\
121 \text { a } 360 \mathrm{dd} \text {. } \\
\text { > } 360 \mathrm{dd}\end{array}$ & $\begin{array}{l}\text { A vencer } \\
\text { Vencidos: } \\
1 \text { a } 60 \mathrm{dd} . \\
61 \text { a } 120 \mathrm{dd} . \\
>120 \mathrm{dd} .\end{array}$ \\
\hline $\begin{array}{l}\text { Critérios para constituição da PECLD } \\
\text { por faixa de vencimento }\end{array}$ & $\operatorname{sim}$ & não & não & parcial \\
\hline $\begin{array}{l}\text { Grau de concentração da carteira de } \\
\text { Contas a Receber }\end{array}$ & $\operatorname{sim}$ & não & $\operatorname{sim}$ & não \\
\hline $\begin{array}{l}\text { Contas a Receber e a PECLD } \\
\text { segregados por instrumento de crédito }\end{array}$ & não & $\operatorname{sim}$ & não & não \\
\hline $\begin{array}{l}\text { Contas a Receber e PECLD segregados } \\
\text { por segmento de mercado }\end{array}$ & não & não & não & não \\
\hline $\begin{array}{l}\% \text { de perda (glosas e devedores } \\
\text { duvidosos) }\end{array}$ & não & não & $\begin{array}{c}\text { parcial. } \\
\text { Para glosas }\end{array}$ & não \\
\hline $\begin{array}{l}\text { Critério para baixa (write-off) de } \\
\text { recebíveis e valores a faturar }\end{array}$ & $\begin{array}{c}\text { parcial } \\
\text { (recebíveis) }\end{array}$ & $\begin{array}{l}\text { parcial (vls. a } \\
\text { faturar) }\end{array}$ & não & não \\
\hline $\begin{array}{l}\text { Indicadores de performance sobre } \\
\text { recebíveis. }\end{array}$ & não & não & $\begin{array}{c}\text { sim. } 5 \\
\text { indicadores }\end{array}$ & $\begin{array}{c}\text { sim. } 4 \\
\text { indicadores }\end{array}$ \\
\hline
\end{tabular}

Fonte: Elaborada pelo autor com base nas demonstrações contábeis da Alliar (2018); Dasa (2018); Fleury (2018); IHP (2018).

\section{Considerações finais}

A partir do exercício de 2018 as empresas brasileiras passaram a divulgar a receita de contrato com cliente em consonância com os preceitos IFRS 15 / CPC 47. Esta pesquisa objetivou contribuir com o mercado de capitais e demais partes interessadas em demonstrar, com profundidade de análise, o funcionamento do ciclo de receita de cliente no complexo segmento de SAD no Brasil, colocando uma luz sobre a necessidade de repensar os critérios de reconhecimento e desreconhecimento de receita com cliente e do disclosure das informações relevantes via demonstrações contábeis e suas notas explicativas. Porém, não se pretendeu esgotar o assunto, haja vista a amplitude e complexidade do mesmo.

Em linha com a percepção de vários autores (CAMPOS, 2017; CARPIS DANI et al., 2017; FAGUNDES, 2017; SOUZA, 2015; TAVARES, 2016; SILVA, 2018; PEREIRA, 2017; SPARGER, 2017; BENAVIDES, 2015; COVA, 2015; KHAMIS, 2016; KNOROVÁ, 2016; MORA et al., 2015; ONCIOIU; AVAKUMOVIC, 2016; OYEDOKUN, 2016; PASQUALE, 2017; PETERS, 2016; SEVERIANO et al., 2017; YEATON, 2015), constatou-se a dificuldade também no segmento de SAD no Brasil em adotar uma norma de aplicação geral em um segmento tão peculiar, principalmente no que tange às notas explicativas de balanço, de forma que as empresas não atenderam à função das demonstrações contábeis como fonte principal de informações para os stakeholders, como defendida por Assaf Neto (2003), Chambers (1969), Damodaran (2012) e Iudícibus (2017).

$\mathrm{O}$ objetivo da pesquisa foi alcançado ao prover respostas às questões da pesquisa, e permitiu concluir que:

a) À exceção dos aspectos de divulgação, as empresas estão aderentes aos requisitos mínimos para reconhecimento, mensuração, registro contábil e divulgação da receita 
com cliente. Ressalte-se que nenhuma das empresas teve ressalva nesse âmbito no parecer dos seus auditores independentes.

b) Há ausência de divulgação de informações obrigatórias e para aquelas divulgadas muitas são insuficientes e/ou sem clareza, prejudicando a comparabilidade.

c) Falta de indicadores que demonstrem o comportamento da carteira de recebíveis.

Assim, para dar mais utilidade às informações divulgadas, torna-se importante que o segmento de medicina diagnóstica busque:

a) Uniformizar a apresentação de notas explicativas, a exemplo de critérios para reconhecimento de perdas e carga tributária incidente sobre as receitas;

b) Declarar o limite de concentração (apetite ao risco) por cliente e mercado, em valor absoluto ou proporcional ao Patrimônio Líquido ou Contas a Receber;

c) Divulgar a estimação das perdas esperadas associadas ao risco de crédito por aging de vencimento, bem como informar os percentuais das perdas com glosas e inadimplência efetivamente observados no período;

d) Incluir em Nota Explicativa informações sobre a régua de provisão e volumetria do contas a receber por aging de vencimento e mercado de atuação.

e) Incluir em Nota Explicativa informações sobre a volumetria do contas a receber por aging de vencimento, mercado de atuação e natureza dos títulos a receber, bem como indicadores de desempenho do ciclo de receitas.

Ficou claro que o segmento de SAD no Brasil precisa evoluir em termos de uniformização de critérios para a constituição de PECLD, assim como para uma padronização do modelo de divulgação através de notas explicativas às demonstrações contábeis. A forma atual de divulgação não dá condições para se comparar as empresas do segmento no que tange aos riscos e gestão do ciclo de receita, pois falta transparência, completude e uniformidade das informações. Perdem os usuários, por não ter informações suficientes e explicativas para a tomada de decisão econômica; perdem as empresas do segmento, por, dessa forma, diminuir a atração de novos investidores, dificultando e/ou encarecendo o seu acesso ao mercado de capitais nacional e internacional.

Está-se diante de um modelo novo de tratamento de receita ainda com pouca ou nenhuma produção científica no campo da ciência contábil; está-se diante de um estudo contábil em um segmento importante para a economia e para a sociedade, com perspectiva de forte crescimento e de novos entrantes, nacionais e internacionais, e pouco estudado em termos contábil-financeiro, muito menos no que tange à receita com cliente; e, por fim, está-se diante de grande oportunidade para a geração de produção científica que amplifique o entendimento do segmento e contribua com a construção de melhores práticas de gestão e para a geração de eficiência de mercado.

Apesar de contemplar a análise da aderência dos principais players no Brasil de medicina diagnóstica, não se deve entender que os resultados aqui obtidos se confirmariam, também, nas demais empresas do segmento. Ainda, por se tratar de uma norma que passou a vigorar recentemente e a pesquisa ter considerado uma demonstração contábil intermediária, as empresas analisadas poderão vir a fazer ajustes para melhor se adequar à IFRS 15 /CPC 47. Para pesquisas futuras sugere-se aplicar este estudo a outros players do setor de saúde, como hospitais e operadoras de planos de saúde.

\section{Referências}

ALLIAR - CENTRO E IMAGEM E DIAGNÓSTICO S/A. Relações com Investidores Relatórios Financeiros. 2017. Disponível em: http://ri.alliar.com/conteudo_pt.asp?idioma= $0 \&$ conta $=28 \&$ tipo $=61714 \& \mathrm{id}=0 \&$ submenu $=0 \& \mathrm{img}=0 \&$ ano $=2017$. Acesso em: 15 ago. 2018 . 
ANAHP - ASSOCIAÇÃO NACIONAL DE HOSPITAIS PRIVADOS. Painel Saúde em números 2018. 2018. Disponível em: https://lms.anahp.com.br/ download/58. Acesso em: 10 ago. 2018 .

ASSAF NETO, Alexandre. Finanças corporativas e valor. São Paulo: Atlas, 2003.

BENAVIDES, Luis. Flattening the Revenue Recognition Standard. 22 abr. 2015. https://doi.org/10.2139/ssrn.2597787

BRASIL. Lei n. 6.404, de 15 de dezembro de 1976. Dispõe sobre as Sociedades por Ações. Brasília, DF. Disponível em: https://www.planalto.gov.br/ccivil_03/ Leis/L6404consol.htm. Acesso em: 29/08/2018.

BRASIL. Lei n. 11.638, de 28 de dezembro de 2007. Altera e revoga dispositivos da Lei no 6.404, de 15 de dezembro de 1976, e da Lei no 6.385, de 7 de dezembro de 1976, e estende às sociedades de grande porte disposições relativas à elaboração e divulgação de demonstrações financeiras. Brasília, 2007. Disponível em: https://www.planalto.gov.br/ccivil_03/_ato 20072010/2007/lei/l11638.htm. Acesso em: 3 jul. 2018.

CAMPOS, Claudinei José Gomes. Método de análise de conteúdo: ferramenta para a análise de dados qualitativos no campo da saúde. Revista Brasileira de Enfermagem, v. 57, n. 5, p. 611614, set.-out. 2004. http://dx.doi.org/10.1590/S0034-71672004000500019

CAMPOS, Lorena Almeida. A. Indicadores de desempenho para organizações da construção civil com adoção da IFRS 15. 2017. 129 f. Dissertação (Mestrado em Ciências Contábeis) Universidade de Brasília, Brasília, 2017.

CARPIS DANI, Andréia.; SANTOS, Cleston Alexandre; PANUCCI FILHO, Laurindo; KLANN, Roberto Carlos. Efeito da adoção antecipada da IFRS 15 na Qualidade da Informação Contábil. Enfoque: Reflexão Contábil, v. 36, n. 2, 2017. https://doi.org/10.4025/enfoque.v36i2.33913

CHAMBERS, Raymond John. Accounting Finance and Management. Sidney: Hogbin Poole, 1969.

CHIZZOTTI, Antônio. Pesquisa em Ciências Humanas e Sociais. São Paulo: Cortez, 2001.

CNS - CONFEDERAÇÃO NACIONAL DA SAÚDE. Serviços de saúde no Brasil cadastrados no MS. Brasília: CNS, 2018. Disponível em: http://cns.org.br/links/DADOS_DO_SETOR.htm. Acesso em: 10 ago. 2018.

CONNER, Brian. The new revenue recognition standard where organizations stand. Healthcare Financial Management, v. 71, n. 10, out. 2017. Disponível em: https://www.hfma.org/Content.aspx?id=56185. Acesso em: 19 mai. 2019.

COVA, Carlos José Guimarães. Os impactos da assimilação da norma internacional de relatório financeiro (IFRS 15), que trata do reconhecimento das receitas de contratos com os clientes, e seus efeitos assimétricos nas demonstrações financeiras das empresas brasileiras. Pensar Contábil, v. 17, n. 64, p. 48-55, set/dez. 2015. https://doi.org/10.4270/ruc.2014318 
CPC - COMITÊ DE PRONUNCIAMENTOS CONTÁBEIS. Pronunciamentos técnicos contábeis 2012/ Comitê de Pronunciamentos Contábeis. Brasília: CFC, 2013. Disponível em: http://www.portalcfc.org.br/wordpress/wp-content/uploads/2013/06/cpc_pronunciamen tos_2012_web.pdf. Acesso em: 4 jul. 2018.

CPC - COMITÊ DE PRONUNCIAMENTOS CONTÁBEIS. Pronunciamento Técnico CPC 47 Receita de Contrato com Cliente - Correlação às Normas Internacionais de Contabilidade - IFRS 15. Brasília: CFC, 2016a. Disponível em: http://static.cpc.aatb.com.br/Documentos/527_CPC_47.pdf. Acesso em: 12 jul. 2018.

CPC - COMITÊ DE PRONUNCIAMENTOS CONTÁBEIS. Pronunciamento Técnico CPC 48 Instrumentos financeiros - Correlação às Normas Internacionais de Contabilidade - IFRS 9. Brasília: CFC, 2016b. Disponível em: http://static.cpc.aatb.com.br/Documentos/530 _CPC_48.pdf. Acesso em: 13 ago. 2018.

DAMODARAN, Aswath. Investment valuation: tools and techniques for determining the value of any assets. New Jersey: Jonh Wiley \& Sons, 2012.

DASA - DIAGNÓSTICOS DA AMÉRICA S/A. Relações com investidores. 2018. Disponível em: http://www.dasa3.com.br/. Acesso em: 15 ago. 2018.

FAGUNDES, Vanessa. O reconhecimento da receita em contratos com clientes com uma abordagem a adoção do CPC 47 (IFRS 15): um estudo comparativo das mudanças das normas em empresas de construção civil e incorporadoras. 2017. 79f. Dissertação (Mestrado em Ciências Contábeis e Atuariais) - Pontifícia Universidade Católica de São Paulo, São Paulo, 2017.

FASB - FINANCIAL ACCOUNTING STANDARDS BOARD. Update 2016-10 - Revenue from Contracts with Customers (Topic 606): Identifying Performance Obligations and Licensing. Delaware, 2016. Disponível em: https://www.fasb.org/jsp/FASB/Document_C/ DocumentPage?cid=1176168066253\&acceptedDisclaimer=true. Acesso em: 14 ago. 2018.

FLEURY S/A. Relações com Investidores - Relatórios Anuais. 2017. Disponível em: http://ri.fleury.com.br/fleury/web/conteudo_pt.asp?idioma=0\&conta=28\&tipo=28881\&id=0\&su bmenu=0\&img=0\&ano=2017. Acesso em: 15 ago. 2018.

GELBCKE, Ernesto Rubens; SANTOS, Ariovaldo dos; IUDÍCIBUS, Sérgio de; MARTINS, Eliseu. Manual de Contabilidade Societária: aplicável à todas as sociedades: de acordo com as normas internacionais e do CPC. 3a. ed. São Paulo: Atlas, 2018.

HENDRICKSEN, Eldon. S.; VAN BREDA, Michael F. Teoria da Contabilidade. 1a. ed. São Paulo: Atlas, 2012.

HOLLOWAY Andrew; SUTTON Jay; SWAFFORD Matt. Healthcare revenue recognition: 5 steps for net revenue modeling and reporting considerations. Healthcare Financial Management: Journal of The Healthcare Financial Management Association, v. 71, n. 1, p. 64-9, jan. 2017.

IBGE - INSTITUTO BRASILEIRO DE GEOGRAFIA E ESTATÍSTICA. Projeção da População por sexo e idades. Rio de Janeiro: IBGE, 2013. Disponível em: https://ww2.ibge.gov.br/home/estatistica/populacao/projecao_da_populacao/2013/default_tab.sht m. Acesso em: 10 ago. 2018. 
IFRS FOUNDATION. The Annotated IFRS ${ }^{\circledR}$ Standards - Standards Required 1 January 2018 - Part A. Londres: IFRS, 2018.

IHP - INSTITUTO HERMES PARDINI S/A. Informações Financeiras - Central de Resultados. IHP, 2017. Disponível em: http://hermespardini.riweb.com.br/listresultados. aspx?idCanal=mBxioS0xtgHGmZimJmnGaA==. Acesso em: 15 ago. 2018.

IUDÍCIBUS, Sérgio de. Teoria da Contabilidade. 11. ed. São Paulo: Atlas, 2015.

IUDÍCIBUS, Sérgio de. Análise de Balanços. 11. ed. São Paulo: Atlas, 2017.

IUDÍCIBUS, Sérgio de; MARTINS, Eliseu; GELBCKE, Ernesto Rubens; SANTOS, Ariovaldo dos. Manual de Contabilidade Societária. 2. ed. São Paulo: Atlas, 2013.

JOHNSON, Leslie. A High-Level Overview of How the New Accounting Standard Update on Revenue Recognition Impacts the United States Healthcare System. Tennessee, 2018. East Tennessee State University. Undergraduate Honors Theses. Paper 456. Disponível em: https://dc.etsu.edu/cgi/viewcontent.cgi?article=1524\&context=honors. Acesso em: 10 set. 2018.

KATZ, David. M. A Headache for Health Care: Consolidation complicates revenue recognition standards adoption. The Magazine for Senior Financial Executives, v. 33, n. 8, out. 2017.

KHAMIS, Amr M. Perception of preparers and auditors on new revenue recognition standard (IFRS 15): evidence from Egypt. Journal of Accounting and Business Dynamics, Dubai, v. 3, n. 2, pp. 1-18, 2016. https://doi.org/10.24815/jdab.v3i2.5383

KNOROVÁ, Katerina. Do Czech Companies Disclose Revenue in Accordance with IFRS Requirements? European Financial and Accounting Journal, v. 11, n. 3, p. 69-84, 2016. https://doi.org/10.18267/j.efaj.163

LOPES, Alexsandro Broedel; MARTINS, Eliseu. Teoria da Contabilidade: Uma nova abordagem. São Paulo: Atlas, 2017.

MAES, Antonio Ivo; CUNHA, Paulo Roberto da; OLINQUEZITCH, José Leônidas. As demonstrações contábeis dos hospitais particulares dos Estado de Santa Catarina na ótica do Princípio da Competência. In: CONGRESSO BRASILEIRO DE CUSTOS, 13. Anais...

ISSN 2358-856X. Belo Horizonte, 30 de outubro e 01 de novembro de 2006.

MARTINS, Gilberto de Andrade; THEÓPHILO, Carlos Renato. Metodologia de investigação científica para ciências sociais aplicadas. 2a. ed. São Paulo: Atlas, 2009.

MATIAS-PEREIRA, José. Manual de Metodologia da Pesquisa Científica. São Paulo: Atlas, 2012.

MCKEE, T. E. New FASB standard addresses revenue recognition considerations. (Financial Accounting Standards Board). Healthcare Financial Management, v. 69, n. 12, 2015. Disponível em: https://www.ncbi.nlm.nih.gov/pubmed/26793947. Acesso em: 10 mai. 2019. 
MORA, Gregori Ranieri Krieger; SOUZA, Carlos Alberto de; DALFIOR, Vanda Aparecida Oliveira. IFRS 15 - Receita de contratos com clientes e seus impactos nas demonstrações financeiras das empresas. In: XVI SIMPÓSIO DE EXCELÊNCIA EM GESTÃO E TECNOLOGIA, 2015. Rio de Janeiro. Anais... Resende: Associação Educacional Dom Bosco, 2015.

MUNTER, Paul. The new revenue recognition standard: implications for healthcare companies. Management Accounting Quarterly, v. 17, n. 2, 30, Wntr.2016.

ONCIOIU, Ionica; AVAKUMOVIC, Julija. Revenue from contracts with customers under IFRS 15: New perspectives on practice. EuroEconomica, 2016, v. 2, n. 35, pp. 31-40.

OYEDOKUN, Godwin. Revenue Recognition Paradox: A Review of IAS 18 and IFRS 15. 24 maio 2016. https://dx.doi.org/10.2139/ssrn.2912250

PASQUALE, Cinthia Ponara Russo. Ajustes às atividades de controles internos em face da adoção do IFRS 15. 2017. 51 f. Dissertação (Mestrado em Ciências Contábeis) - Fundação Alvares Penteado - Fecap, São Paulo, 2017.

PEREIRA, Patricia de Monteiro Ramalho. Análise da implementação do pronunciamento CPC 47 na perspectiva da gestão da inovação de processo. 2017, 46 f. Dissertação (Mestrado em Administração) - Fundação Getúlio Vargas, São Paulo, 2017.

PETERS, Maxime. The new IFRS 15 Standard: Implementation Challenges for Belgian Companies. 2016, 123 f. Dissertação (Master en sciences de gestion) - University of Liége, Bélgica, 2016.

PYLE, William W.; WHITE, John Arch.; LARSON, Kermit D.; ZIN, Michael. Fundamental Accounting Principles. 3a. ed. Georgetown: Irwin-Dorsey, 2016.

RFB - RECEITA FEDERAL DO BRASIL. Instrução Normativa IN RFB n. 1.700, de 14 de março de 2017. Dispõe sobre a determinação e o pagamento do imposto sobre a renda e da contribuição social sobre o lucro líquido das pessoas jurídicas e disciplina o tratamento tributário da Contribuição para o PIS/Pasep e da Cofins no que se refere às alterações introduzidas pela Lei $\mathrm{n}^{\circ}$ 12.973, de 13 de maio de 2014. Brasília, 2017a. Disponível em: http://normas.receita.fazenda.gov.br/sijut2consulta/link.action?visao=anotado\&idAto $=81268 \# 17$ 06802. Acesso em: 31 ago. 2018.

SEVERIANO, Larissa Sales; ALENCAR, Roberta Carvalho de; GARCIA, Editinete André da Rocha. Adoção da IFRS 15 - Revenue from Contracts with Customers em empresas brasileiras: principais obstáculos. Ciências Sociais Aplicadas em Revista, v. 17, n. 32, p. 146-166, 2017. ISSN 1982-3037 (versão eletrônica).

SILVA, Adriele Soares da. Os impactos da IRFS 15 no setor de transporte. 2008. 20 f. Trabalho de Conclusão de Curso (Graduação em Ciências Contábeis) - Universidade Federal de Uberlândia, Uberlândia, 2018.

SILVA, Wilson Xavier da. Reconhecimento de receitas nos hospitais gerais da região de Sorocaba. São Paulo, 2012. Dissertação (Mestrado em Ciências Contábeis e Atuariais). Pontifícia Universidade Católica de São Paulo, 2012. 
SOUZA, Edimilson Patrocinio de. Contabilidade de contratos de construção e de incorporação imobiliária: de acordo com as IFRS. São Paulo: Atlas, 2015.

SPARGER, John Robert. Revenue Recognition Considerations for Producers and Natural Gas Processors Under ASC 606. Petroleum Accounting and Financial Management Journal, v. 36, n. 2, p. 112-133, 2017.

TAVARES, Thiago Napolitano. A implementação do IFRS 15 no Brasil: análise das mudanças nos processos e controles internos para reconhecimento da receita nos contratos de construção. 2016. 74f. Dissertação (Mestrado em Controladoria Empresarial) - Universidade Presbiteriana Mackenzie, São Paulo, 2016.

YAMAMOTO, Marina Mitiyo; PACCEZ, João Domiraci Paccez; MALACRIDA, Mara Jane Contrera. Fundamentos da Contabilidade. São Paulo: Saraiva, 2011.

YEATON, Kathryn. A new world revenue recognation: revenue from contracts with customers. The CPA Journal, v. 85, n. 7, p. 50-54, 2015. 